\title{
Probable Case Status
}

National Cancer Institute

\section{Source}

National Cancer Institute. Probable Case Status. NCI Thesaurus. Code C99271.

The participant is a probable case for the phenotype under consideration. 